\title{
Morphological features and mucin expression profile of breast carcinomas with signet- ring cell differentiation
}

\section{Carla Bartosch ${ }^{\text {ab }}$ NunoMendes ${ }^{c}$ Elisabete Rios ${ }^{b}$ Marta Rodrigues $^{b}$ Catarina Eloy $^{c}$ Celso A. Reis ${ }^{\text {cd }}$ Isabel Amendoeira ${ }^{\text {bc }}$}

\author{
a Department of Pathology, Portuguese Oncology Institute-Porto, Portugal \\ b Department of Pathology, Centro Hospitalar São João, Porto, Portugal \\ c IPATIMUP, Institute of Molecular Pathology and Immunology, Porto, Portugal \\ d Porto Medical Faculty, University of Porto, Portugal\#To whom correspondence should be \\ addressed: Celso A. Reis
}

Originally published in Pathol Res Pract. 2015 Aug;211(8):588-95. doi: 10.1016/j.prp.2015.05.003. Epub 2015 May 27.

Keywords: Breast carcinomaSignet-ring cellMucinsMUC1MUC2MUC6 


\section{ABSTRACT}

Signet-ring cells are relatively common in breast cancers but are frequently overlooked. Although previously defined as a subtype of mucin producing carcinomas, breast carcinomas with signet-ring cell (SRC) differentiation nowadays are not considered a distinct entity.

The objective of the present study was to characterize the morphological features and mucin expression profile of breast carcinomas with SRC differentiation. All breast carcinomas diagnosed at Centro Hospitalar S. Joao between 1996 and 2006 in which the pathology report mentioned the presence of SRCS $(n=11)$ and four mucinous carcinomas were included in the study. The frequency of SRCs and immunohistochemistry expression of MUC1/MUC2/MUC 5 AC/MUC6 were evaluated.

We confirmed that SRC differentiation can occur in different histological types, including ductal, lobular, mucinous and metaplastic carcinomas. The proportion of SRCs was highly variable (range: 8-70\%). Tumors encompassed SRCs of intracytoplasmic lumina and goblet-cell type. A higher percentage of SRCs was associated with lymphovascular invasion $(p=0.047)$. All tumors expressed cytoplasmic and membranous $M C_{1}$. Secretory mucins were more frequent in mucinous carcinomas and in carcinomas with extensive SRC differentiation.

We conclude that besides the usefulness of mucin immunodetection for the differential diagnosis of carcinomas with SRC differentiation of breast origin, it is important to report SRC differentiation regardless of histological type because of its intrinsic prognostic value.

\section{Highlights}

- Morphology and mucin expression of breast carcinomas with SRCs were characterized.

- SRC differentiation was present in different histological types of breast carcinoma.

- SRCs of the intracytoplasmic lumina type and goblet type were identified.

- Cytoplasmic and membranous MUC1 was expressed in all tumors.

- Secretory mucin expression varied with histological type.

\section{INTRODUCTION}

Breast carcinomas with signet-ring cell (SRC) differentiation, although previously defined as a subtype of mucin producing carcinomas, are no longer considered by the World Health Organization (WHO) to represent a distinct entity [1], [2]. Nevertheless, SRC differentiation has been associated with a greater frequency of axillary lymph nodal involvement and a higher mortality rate than those observed in other forms of breast cancer [3], [4], [5].

SRCs are characterized by a well-defined globule of mucinous material that causes peripheral displacement of the nucleus. SRCs may have different morphological characteristics: intracytoplasmic lumina containing some eosinophilic material or apparently empty "intracytoplasmic lumina type"; pale, homogeneous eosinophilic cytoplasm - "eosinophilic type"; abundant, finely vacuolated and faintly basophilic cytoplasm - "goblet-cell type" [6]. 
Mucins are high molecular weight glycoproteins, classified into two main groups: secretory (MUC2, $M U C_{5} A C, M U C_{5} B$, and $\left.M U C 6\right)$ and transmembrane mucins ( $M U C_{1}, M U C_{3} A, M U C_{3} B, M U C_{4}$, $M U C_{12}, M U C_{16}$ and $M_{17} C_{17}$ [7]. Much interest has been paid to the expression of mucins because of their potential role in distinguishing metastasis of breast carcinoma from those of gastrointestinal origin, as well as for their prognostic role in breast cancer [8], [9], [10].

The aim of the present study was to characterize the morphological features and mucin expression profile of breast invasive carcinomas with SRC differentiation.

\section{MATERIALS AD METHODS}

Following ethical approval by the Ethical Committee for Health of Centro Hospitalar S. João (CHSJ), breast invasive carcinomas diagnosed between 1996 and 2006, in which the pathology report mentioned the presence of SRC $(n=11)$, were retrieved from CHSJ surgical pathology database. These represented $1.2 \%$ of all breast invasive carcinomas diagnosed in the same period of time. Four representative mucinous carcinomas were randomly selected for the study. Clinical information was collected from the medical records, and the pathological material was reviewed according to the current WHO guidelines [2]. In each case, the tumor tissue had been fixed in $10 \%$ buffered formalin and embedded in paraffin; $3-\mu \mathrm{m}$ thick sections were stained with hematoxylineosin. Representative sections of the tumors were stained with periodic acid-Schiff with diastase digestion (PAS-D). The presence of SRC in each tumor was evaluated quantitatively by two observers (CB and $C E$ ) that independently determined the percentage of SRCs among the total number of tumor cells assessed in ten high power fields centered in SRCs hot spots.

Immunohistochemical assays were carried out using the avidin-biotin method as previously described [11]. MUC1, MUC5AC, MUC6, and MUC2 were detected using monoclonal antibodies HMFG [12], CLH2 [13], CLH 5 [14], and $\mathrm{PMH}_{1}$ [15], respectively. Estrogen receptor (ER) (clone: $\mathrm{SP}_{1}$, Neomarkers, Fremont, CA, USA), E-cadherin (clone: ${ }_{4} \mathrm{~A}_{2} \mathrm{C}_{7}$, Zymed/Invitrogen, Carlsbad, CA, USA), CD56 (clone: 1B6, Novocastra, Newcastle, UK), synaptophysin (27G12, Novocastra, Newcastle, UK) and GCDFP-15 (clone: $23 \mathrm{~A}_{3}$, Thermo Scientific, Fremont, CA, USA) expression were also evaluated. A case was considered ER positive when more than $1 \%$ of the tumor cells were positive. For the remaining antibodies, a 5\% cut-off was used [16].

Data was analyzed using STATA (STATACorp, Texas, USA), version 12.1. Mann-Whitney and Kruskal-Wallis rank tests were used to compare mean SRC percentage between tumors with and without lymphovascular invasion, lymph node metastases, and tumor grade. Spearman correlation coefficient was used to test the association between SRC percentage and tumor size. A $p$ value equal or less than 0.05 was considered significant.

\section{RESULTS}

The clinical and pathological features of the 15 cases are summarized in Table 1 . The mean and median ages were 65.4 and 64 years, respectively, with a range of $34-85$ years. The most frequent location of tumors was the upper outer quadrant of the breast. All patients were submitted to diagnostic fine needle aspiration or core biopsy. Of these only two core biopsies were available for review and showed signet ring cells representation. Of the remaining biopsies, three also mentioned signet rings in the report. Lumpectomy $(n=5)$ or total mastectomy $(n=10)$ was 
performed, with sentinel node biopsy $(n=12)$ followed by nodal dissection whenever appropriate $(n$ = 9). Three patients did not undergo lymph node evaluation. Four patients were treated with chemotherapy, eight patients underwent local radiotherapy and nine received hormone therapy. For two patients, data on adjuvant treatment were not available, and for six, there was no information concerning hormone treatment. The median follow-up time was 87 months, ranging from 2 months to 12.6 years. The three patients who died of disease had distant tumor spread at diagnosis.

The size of the tumors ranged from 0.9 to $8.5 \mathrm{~cm}$ (mean: $3.3 \mathrm{~cm}$ ) in maximum diameter. The gross specimens of the 11 cases identified as displaying SRCs (Table 1 - cases 1-11) were invariably described as whitish-gray, ill-defined masses. In the mucinous carcinoma cases, the lesions were described as gelatinous masses. Histologically, seven of the 11 tumors with SRCs were classified as ductal carcinoma (one of which rich in osteoclast-like giant cells), three as lobular carcinoma (two pleomorphic and one classical) and one as metaplastic carcinoma (with mixed squamous cell and spindle cell components). All but one (the metaplastic carcinoma) of these 11 tumors had easily recognizable areas of SRC that constituted variable proportions of the total of tumor cells, ranging from $15 \%$ to $70 \%$. SRCs were also identified in mucinous carcinomas, ranging from $8 \%$ to $17 \%$. Two types of SRCs were observed: SRCs of the intracytoplasmic lumina type and of goblet cell type (Fig. 1). Intracellular mucin was confirmed by PAS-D staining in all tumors. Extracellular mucin was only seen in mucinous carcinomas.

In ductal carcinomas, the areas containing the highest concentrations of signet-ring cells were characterized by a more diffuse growth pattern, frequently with a solid, cohesive aspect (Fig. 2A). Areas of well-formed neoplastic acini containing SRCs were also seen. In ductal carcinomas, the SRCs had a variable appearance from case to case, some being of goblet cell and others of intracytoplasmic lumina type. Two ductal carcinomas had ductal carcinoma in situ containing numerous SRC (Fig. 2B). In the three lobular carcinomas SRC had intracytoplasmic lumina type morphology, and, although present in the "indian filing" pattern, were especially abundant in more densely cellular areas (Fig. 3A and B). The metaplastic carcinoma had SRCs of the goblet cell type.

In the four mucinous carcinomas few SRCs, both of the goblet cell and intracytoplasmic lumina type, could be seen scattered in tumor islands amongst lakes of extracellular mucin, the percentage being higher in areas of solid sheets of cells with little extracellular mucin (Fig. $4 \mathrm{~A}-\mathrm{C}$ ).

Considering the cases identified initially as displaying SRCs (Table 1 - cases 1-11), a higher percentage of SRCs was significantly associated with lymphovascular invasion (mean SRCs percentage in tumors without versus with lymphovascular invasion: $30.0 \%$ and $52.7 \%$, respectively, $p=0.047$ ). Although there was a trend for higher SRC percentage in patients with lymph node metastases, this was not statistically significant (mean SRC percentage in tumors without versus with lymph node metastases: $39.3 \%$ and $47.0 \%, p=0.462$ ). There is no significant association between SRC\% and tumor grade (mean SRC percentage by grade: G1 $=37.3 \%, G_{2}=53.0 \%, G_{3}=$ $36.0 \%, p=0.445)$ or size $(r s=0.42 ; p=0.146)$.

Regarding the mucin immunostaining profile (Table 2), evaluation was focused preferentially in SRCs rich areas. All tumors showed cytoplasmic and membranous $M C_{1}$ immunoreactivity, not 
limited to SRCs but diffusely expressed throughout the tumor (Figs. ${ }_{3} C$ and ${ }_{4} D$ ). In tumors presenting intracytoplasmic lumina type SRCs, there was accentuation of the lumina membrane with luminal MUC1 expression. In mucinous carcinomas we observed that $\mathrm{MUC}_{1}$ had a strong intracytoplasmic expression in the cells within the tumor cell nests, not limiting itself to the peripheral cells, although in one case, we observed a slight enhancement in the peripheral area.

The secretory mucins expression patterns varied between histological types, the proportion of positive tumor cells being highly variable in the different tumors. MUC2 (Figs. $2 \mathrm{C}$ and $3 \mathrm{D}$ ) was expressed in three ductal and all three lobular carcinomas, although just focally in one ductal and in one lobular carcinoma. MUC5AC was negative in all cases except in one mucinous carcinoma. MUC6 (Figs. 2D and 4F) was expressed in three ductal carcinomas and three mucinous carcinomas.

All tumors but one (the metaplastic carcinoma) were positive for estrogen receptors. E-cadherin was negative in the three lobular carcinomas. Synaptophysin expression was observed in one mucinous carcinoma and three ductal carcinomas with extensive SRC differentiation. Two of these ductal carcinomas exhibited strong synaptophysin expression (Fig. 2E) and one had focal cell immunoreactivity. The expression of GCDFP-15 was predominantly cytoplasmatic and often stained signet-ring cell content. Two out of three lobular carcinomas, three out of seven ductal carcinomas, and all four mucinous carcinomas showed GCDFP-15 expression. Synaptophysin expression coexisted with GCDFP-15 staining in two cases (Fig. 2F).

\section{DISCUSSION}

Carcinomas with SRC differentiation were previously considered a subtype of mucin producing carcinomas, some authors arguing in favor of their histogenetic association to lobular carcinoma and others to ductal carcinoma [3], [4], [6], [17], [18], [19], [20], [21]. In our series, we found SRCs in different histological types of invasive breast carcinoma (ductal, lobular, metaplastic and mucinous), supporting the current WHO suggestion that carcinomas with SRC differentiation are not a distinct entity [2]. The extent of SRCs present in the tumors is variable, being most frequently focal and in some cases constituting the majority of the tumor cells. In the present series, we observed as few as $8 \%$ SRCs in one mucinous carcinoma, to over 50\% in one lobular and three ductal carcinomas. In areas where SRCs predominate, the tumors showed a more diffuse or solid infiltrative growth pattern. The criteria that we used for cell counting considered only the classical signet-ring shaped cells. Thus, the percentage of SRC present in the tumors may have been underestimated since the classical appearance depends upon the amount of mucin in the cells and the level of the cell's histological cross-section.

Scattered SRCs are relatively common in breast carcinomas, particularly in lobular carcinomas, but are rarely reported. Some studies showed that carcinomas with extensive SRC differentiation (previously called SRC carcinomas) have distinctive clinical and pathologic features that warranted their individualization as an aggressive subtype of breast cancer [3], [4], [5]. However, there has never been a consensus regarding the extent of SRC differentiation that should be used for diagnosis [3], [4], [22]. Some authors demonstrated that a cut-off of $10 \%$ SRCs in lobular carcinomas separated tumors with a significant impact on prognosis and claimed that the percentage of SRC should therefore be reported as one of several prognostic variables [5]. In our small study, we also showed that a higher SRC percentage in tumors was significantly associated with the presence of lymphovascular invasion, and showed a trend toward the presence of lymph 
node metastases, reflecting a more aggressive behavior. These results must be interpreted with caution given the limited number of cases of the present series, as well as putative selection bias.

There was $\mathrm{MUC}_{1}$ immunoreactivity in all breast carcinomas irrespective of their histological type in accordance with most studies [9], [10], [23], [24]. MUC1 is a large trans-membrane highly glycosylated mucin which is expressed at the apical pole of normal cells in glandular epithelia. In malignancies, MUC1 is overexpressed on the entire cell surface, and most cases display aberrant cytoplasmic expression. Prominent aberrant cytoplasmic MUC1 expression has been associated with poorer outcome [9], [25], thus leading some authors to consider not only the positivity of expression but also its subcellular localization (luminal, membranous and/or cytoplasmic) [9]. In the present series, MUC 1 expression was both cytoplasmic and membranous in all tumors. MUC 1 expression was not limited to the SRCs; it was present diffusely throughout the whole tumors, but in intracytoplasmic lumina type SRCs, there was a strong accentuation of immunoreactivity at the luminal membrane. Recent studies have shown that $\mathrm{MUC}_{1}$ can interact with $\beta$-catenin competitively for E-cadherin, thus destabilizing intercellular junctions and favoring metastatic dissemination [26]. Some studies showed that MUC1 aberrant expression may be negatively correlated with the normal expression of E-cadherin, particularly in gastric cancers [27], [28]. However, in most of the cases herein described, excluding lobular carcinomas, there was coexpression of normal membranous E-cadherin and cytoplasmic MUC1.

Few studies addressed mucin staining profiles in breast carcinomas with SRC differentiation. Nguyen et al. [22], in their series of six breast SRC carcinomas, observed that all cases expressed MUC 1 and that there was a variable expression of MUC2 (33.3\%), MUC5AC (16.7\%) and MUC6 (33.3\%). Peiguo et al. [8], in their series of 21 breast SRC lobular carcinomas, reported that all cases were positive for $M U C_{1}$ and all except one were negative for $M U C_{2}$ and $M U C_{5} A C$. Thus, a subset of breast carcinomas with SRC differentiation can express secretory mucins, as also shown in our series. Mucin expression profile can be helpful in the distinction of primary and metastatic breast carcinoma with SRC differentiation from a metastatic signet-ring cell carcinoma of gastrointestinal origin, since $M U C_{1}$ is rare and secretory mucins are frequently expressed in the latter [8], [22]. Moreover, ER and GCDFP-15 were useful markers consistent with mammary origin expressed in most of our carcinomas with SRC differentiation.

Some studies have demonstrated that mucinous carcinomas have a different secretory mucin expression profile than non-mucinous carcinomas, in particular, ductal invasive carcinomas [23], [24], [29], [30], [31], [32]. The epithelial cells of mucinous carcinomas were found to strongly express $M U C_{2}$ and MUC6 and sometimes MUC ${ }_{5} A C$, three of the secreted gel-forming mucins, which are infrequently expressed in invasive ductal carcinomas of no special type. Indeed, the four mucinous carcinomas of our series expressed MUC2, three expressed MUC6, and one expressed MUC5AC. At variance with this, only two out of six ductal carcinomas expressed secretory mucins, these being the cases with higher number of SRCs. The production of remarkable amounts of MUC2 in mucinous carcinomas is thought to act as a barrier that interferes with invasion of the adjacent parenchyma by the malignant cells; this assumption is advanced as a reason for the less aggressive behavior of mucinous carcinomas [9], [31]. In contrast, MUC2 expression in invasive ductal carcinomas, although uncommon, has been reported to be associated with aggressive tumor behavior [33]. These associations with diverse biological features may stem from the role played by specific glycosylation carried by mucins within each different carcinoma subtypes [34], [35]. 
Curiously, in mucinous carcinomas, MUC2 is detected both in the cells' cytoplasm and in the extracellular mucin deposits, whereas MUC6 expression is absent in the extracellular mucin. This may be due to the fact that the anti-MUC6 antibody used in the present study detects an epitope within the mucin protein core [14] and therefore loses its reactivity once the mucin core is fully glycosylated and secreted in some cells.

Interestingly, two ductal carcinomas with widespread SRC differentiation also showed strong synaptophysin expression, raising the hypothesis of neuroendocrine differentiation, also described in association with other mucin-producing carcinomas of the breast [36]. Of note, one of the four mucinous carcinomas in our series was also synaptophysin positive. Finally, we also observed the coexpression of synaptophysin and GCDFP-15 in signet ring cells of ductal and lobular carcinomas, a finding similar to that of Sapino et al., whose study documented this co-expression in signet ring cells of solid papillary carcinomas [37].

\section{CONCLUSION}

SRCs can occur in different histological types of breast carcinomas, including ductal, lobular, metaplastic, and mucinous. SRCs are associated with vascular invasion, which may represent an early marker of tumor dissemination; thus it is important to report SRC differentiation regardless of the histological type. Our immunohistochemistry results suggest that mucin expression profile varied with breast carcinoma histological types and show that carcinomas with SRC differentiation can express both transmembrane and secretory mucins.

\section{ACKNOWLEDGEMENTS}

We especially thank Professor Sobrinho-Simões for the careful review of the manuscript.

IPATIMUP integrates the i3S Research Unit, which is partially supported by FCT, the Portuguese Foundation for Science and Technology. This work is funded by FEDER funds through the Operational Program for Competitiveness Factors-COMPETE and National Funds through the FCTFoundation for Science and Technology, under the projects: PEst-C/SAU/LAooo3/2013 and PTDC/BBB-EBI/0786/2012. 


\section{REFERENCES}

[1] F.A. Tavassoli, P. Deville, Pathology and Genetics of Tumours of the Breast and Female Genital Organs, IARC Press, Lyon, 2003.

[2] S.R. Lakhani,I.O. Ellis, S.J. Schnitt, P.H. Tan,M.J. van deVijver,WHO Classification of Tumours of the Breast, IARC Press, Lyon, 2012.

[3] M.J. Merino, V.A. Livolsi, Signet ring carcinoma of the female breast: a clinicopathologic analysis of 24 cases, Cancer 48 (1981) 1830-1837.

[4] M.T. Hull, I.S. Seo, J.S. Battersby, J.F. Csicsko, Signet-ring cell carcinoma of the breast: a clinicopathologic study of 24cases,Am.J.Clin. Pathol.73(1980)31-35.

[5] A.R. Frost, S. Terahata, I.T. Yeh, R.S. Siegel, B. Overmoyer, S.G. Silverberg, The significance of signet ring cells in infiltrating lobular carcinoma of the breast, Arch. Pathol. Lab. Med. 119 (1995) $64-68$.

[6] J.S. Steinbrecher, S.G. Silverberg, Signet-ring cell carcinoma of the breast. The mucinous variant of infiltrating lobular carcinoma, Cancer 37 (1976) 828-840.

[7] N. Moniaux, F. Escande, N. Porchet, J.P. Aubert, S.K. Batra, Structural organization and classification of the human mucin genes, Front. Biosci. 6 (2001) D1192-D1206.

[8] P.G. Chu, L.M. Weiss, Immunohistochemical characterization of signet-ring cell carcinomas of the stomach, breast, and colon, Am. J. Clin. Pathol. 121 (2004) 884-892.

[9] E.A. Rakha, R.W. Boyce, D. Abd El-Rehim, T. Kurien, A.R. Green, E.C. Paish, J.F. Robertson, I.O. Ellis, Expression of mucins ( $M U C_{1}, M U C_{2}, M_{3} C_{3}, M U C_{4}, M U C_{5} A C$ and $M U C_{6}$ ) and their prognostic significance in human breast cancer, Mod. Pathol. 18 (2005) 1295-1304.

[10] S.K. Lau, L.M. Weiss, P.G. Chu, Differential expression of MUC1, MUC2, and MUC5AC in carcinomas of various sites: an immunohistochemical study, Am. J. Clin. Pathol. 122 (2004) 61-69.

[11] B. Ferreira, N.T. Marcos, L. David, J. Nakayama, C.A. Reis, Terminal alpha1,4- linked Nacetylglucosamine in Helicobacter pylori-associated intestinal metaplasia ofthe human stomach and gastric carcinoma cell lines,J. Histochem. Cytochem. 54 (2006) 585-591.

[12] J. Taylor-Papadimitriou, J. Burchell, D.W. Miles, M. Dalziel, MUC1 and cancer, Biochim. Biophys. Acta 1455 (1999) 301-313.

[13] C.A. Reis, L. David, P.A. Nielsen, H. Clausen, K. Mirgorodskaya, P. Roepstorff, M. SobrinhoSimoes, Immunohistochemical study of MUC 5 AC expression in human gastric carcinomas using a novel monoclonal antibody, Int. J. Cancer 74 (1997) 112-121.

[14] C.A. Reis, L. David, F. Carvalho, U. Mandel, C. de Bolos, E. Mirgorodskaya, H. Clausen, M. Sobrinho-Simoes, Immunohistochemical study ofthe expression of 
MUC6 mucin and co-expression of other secreted mucins ( $M U C_{5} A C$ and $M U C_{2}$ ) in human gastric carcinomas, J. Histochem. Cytochem. 48 (2000) 377-388.

[15] C.A. Reis, T. Sorensen, U. Mandel, L. David, E. Mirgorodskaya, P. Roepstorff, J. Kihlberg, J.E. Hansen, $\mathrm{H}$. Clausen, Development and characterization of an antibody directed to an alpha-Nacetyl-d-galactosamine glycosylated MUC2 peptide, Glycoconjug. J. 15 (1998) 51-62.

[16] M.B. Pereira, A.J. Dias, C.A. Reis, F.C. Schmitt, Immunohistochemical study of the expression of MUC 5 AC and MUC6 in breast carcinomas and adjacent breast tissues, J. Clin. Pathol. 54 (2001) 210-213.

[17] M. Harris, S. Wells, K.S. Vasudev, Primary signet ring cell carcinoma of the breast, Histopathology 2 (1978) 171-176.

[18] S.M. Liu, D.R. Chen, Signet-ring cell carcinoma of the breast, Pathol. Int. 50 (2000) 67-70.

[19] V. Srinivas, H. Subramanya, B. Rajaram, P. Vincent, R. Rai, Signet ring carcinoma of the breast: an uncommon type of breast carcinoma, MJAFI 61 (2005) 84-85.

[20] K. Izuishi, S. Imoto, T. Hasebe, Signet ring cell carcinoma associated with invasive ductal carcinoma of the breast: a case report, Breast Cancer 6 (1999) 223-226.

[21] E.R. Fisher, R. Brown, Intraductal signet ring carcinoma. A hitherto undescribed form of intraductal carcinoma of the breast, Cancer 55 (1985) 2533-2537.

[22] M.D. Nguyen, B. Plasil, P. Wen, W.L. Frankel, Mucin profiles in signet-ring cell carcinoma, Arch. Pathol. Lab. Med. 130 (2006) 799-804.

[23] S. Matsukita, M. Nomoto, S. Kitajima, S. Tanaka, M. Goto, T. Irimura, Y.S. Kim, E. Sato, S. Yonezawa, Expression of mucins ( $M U C_{1}, M U C_{2}, M U C_{5} A C$ and $\left.M U C_{6}\right)$ in mucinous carcinoma ofthe breast: comparison with invasive ductal carcinoma, Histopathology 42 (2003) 26-36.

[24] J.S. Chu,K.J. Chang,Mucinexpressioninmucinous carcinoma and other invasive carcinomas of the breast, Cancer Lett. 142 (1999) 121-127.

[25] J.J. Rahn, L. Dabbagh, M. Pasdar, J.C. Hugh, The importance of MUC1 cellular localization in patients with breast carcinoma: an immunohistologic study of 71 patients and review of the literature, Cancer 91 (2001) 1973-1982.

[26] Z. Yuan, S. Wong, A. Borrelli, M.A. Chung, Down-regulation of $\mathrm{MUC}_{1}$ in cancer cells inhibits cell migration by promoting E-cadherin/catenin complex formation, Biochem. Biophys. Res. Commun. 362 (2007) 740-746.

[27] T. Ohno, R. Aihara, Y. Kamiyama, E. Mochiki, T. Asao, H. Kuwano, Prognostic significance of combined expressionofMUC 1 and adhesionmolecules inadvanced gastric cancer, Eur. J. Cancer 42 (2006) 256-263. 
[28] M. Tanaka, Y. Kitajima, S. Sato, K. Miyazaki, Combined evaluation of mucin antigen and Ecadherin expression may help select patients with gastric cancer suitable for minimally invasive therapy, Br. J. Surg. 90 (2003) 95-101.

[29] J.T. O'Connell, Z.M. Shao, E. Drori, C.B. Basbaum, S.H. Barsky, Altered mucin expression is a field change that accompanies mucinous (colloid) breast carcinoma histogenesis, Hum. Pathol. 29 (1998) 1517-1523.

[30] C. Sonora, D. Mazal, N. Berois, M.P. Buisine, L. Ubillos, M. Varangot, E. Barrios, J. Carzoglio, J.P. Aubert, E. Osinaga, Immunohistochemical analysis of $M U C_{5} B$ apomucin expression in breast cancer and non-malignant breast tissues, J. Histochem. Cytochem. 54 (2006) 289-299.

[31] N.V. Adsay, K. Merati, H. Nassar, J. Shia, F. Sarkar, C.R. Pierson, J.D. Cheng, D.W. Visscher, R.H. Hruban, D.S. Klimstra, Pathogenesis of colloid (pure mucinous) carcinoma of exocrine organs: Coupling of gel-forming mucin (MUC2) production with altered cell polarity and abnormal cellstroma interaction may be the key factor in the morphogenesis and indolent behavior of colloid carcinoma in the breast and pancreas, Am. J. Surg. Pathol. 27 (2003) 571-578.

[32] N. Kato, Y. Endo, G. Tamura, Y. Katayama, T. Motoyama, Mucinous carcinoma of the breast: a multifaceted study with special reference to histogenesis and neuroendocrine differentiation, Pathol. Int. 49 (1999) 947-955.

[33] M.D. Walsh, M.A. McGuckin, P.L. Devine, B.G. Hohn, R.G. Wright, Expression of MUC2 epithelial mucin in breast carcinoma, J. Clin. Pathol. 46 (1993) 922-925.

[34] S. Pinho, N.T. Marcos, B. Ferreira, A.S. Carvalho, M.J. Oliveira, F. Santos-Silva, A. HarduinLepers, C.A. Reis, Biological significance of cancer-associated sialyl-Tn antigen: modulation of malignant phenotype in gastric carcinoma cells, Cancer Lett. 249 (2007) 157-170.

[35] C. Gomes, H. Osorio, M.T. Pinto, D. Campos, M.J. Oliveira, C.A. Reis, Expression of ST3GAL4 leads to $\mathrm{SLe}(\mathrm{x})$ expression and induces c-Met activation and an invasive phenotype in gastric carcinoma cells, PLoS ONE 8 (2013) e66737.

[36] G.M. Tse, T.K. Ma, W.C. Chu, W.W. Lam, C.S. Poon, W.C. Chan, Neuroendocrine differentiation in pure type mammary mucinous carcinoma is associated with favorable histologic and immunohistochemical parameters, Mod. Pathol. 17 (2004) 568-572.

[37] A. Sapino, L. Righi, P. Cassoni, M. Papotti, P. Gugliotta, G. Bussolati, Expression of apocrine differentiation markers in neuroendocrine breast carcinomas of aged women, Mod. Pathol. 14 (2001) 768-776. 


\section{FIGURES}

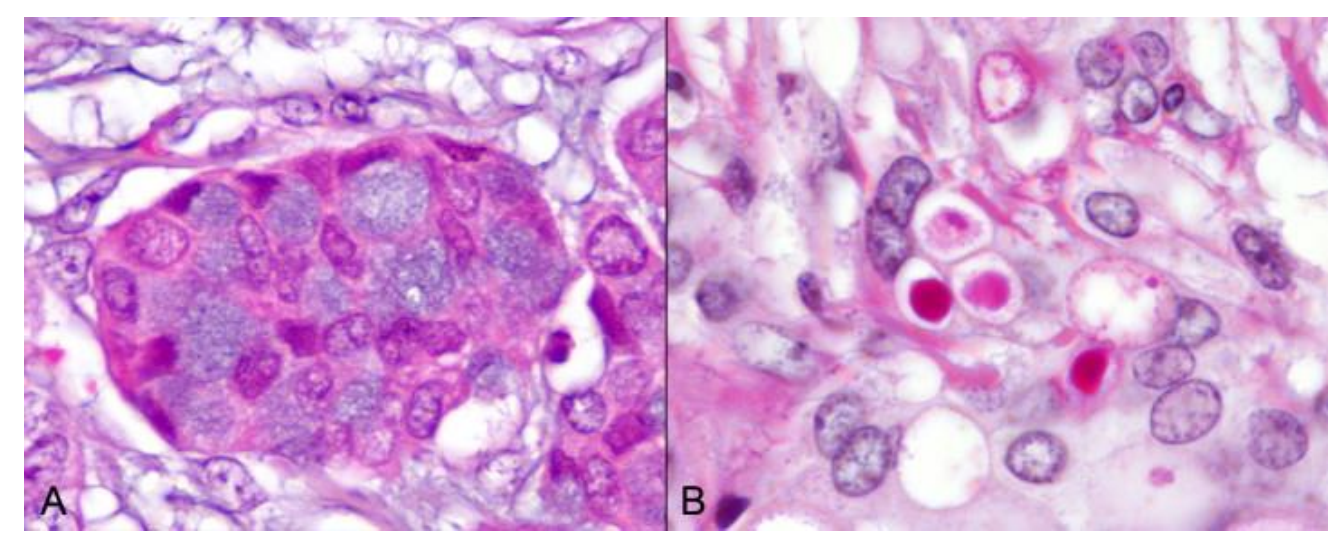

Fig. 1. The typical morphology signet-ring cells of the goblet-cell type (A: H\&E, 100x) and of the intracytoplasmic lumina type (B: PAS-D, 100x). 


\section{5}

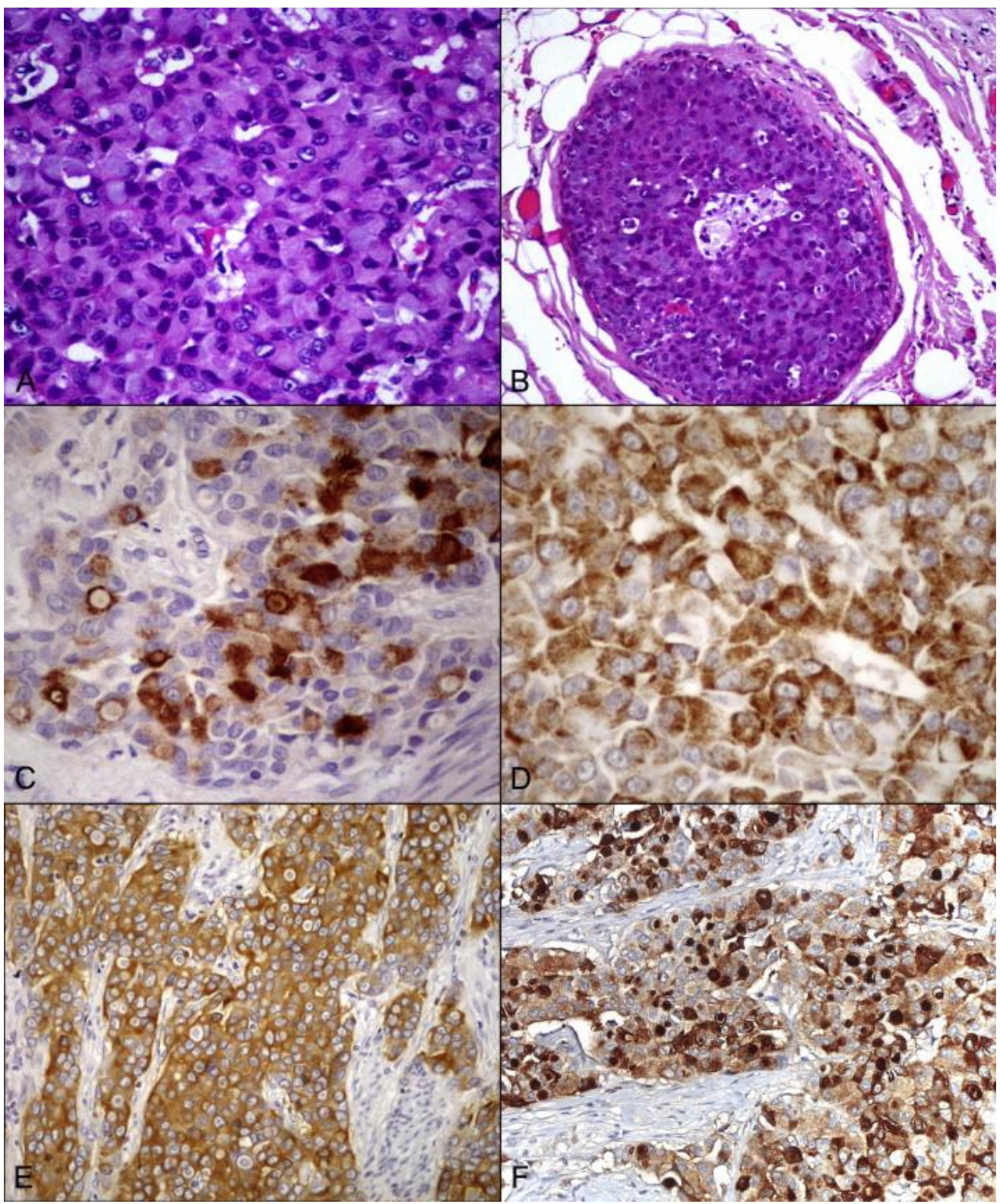

Fig. 2. Ductal carcinoma with extensive signet-ring cell differentiation, both in the invasive areas, showing a solid growth pattern ( $\mathrm{A}: \mathrm{H} \& \mathrm{E}, 40 \mathrm{x})$, and in the in situ component (B: $\mathrm{H} \& \mathrm{E}, 20 \mathrm{x})$. There is MUC2 (C: 40x) MUC6 (D: 40x) and synaptophysin (E: 20x) and GCDFP-15 (F: 20x) expression. 

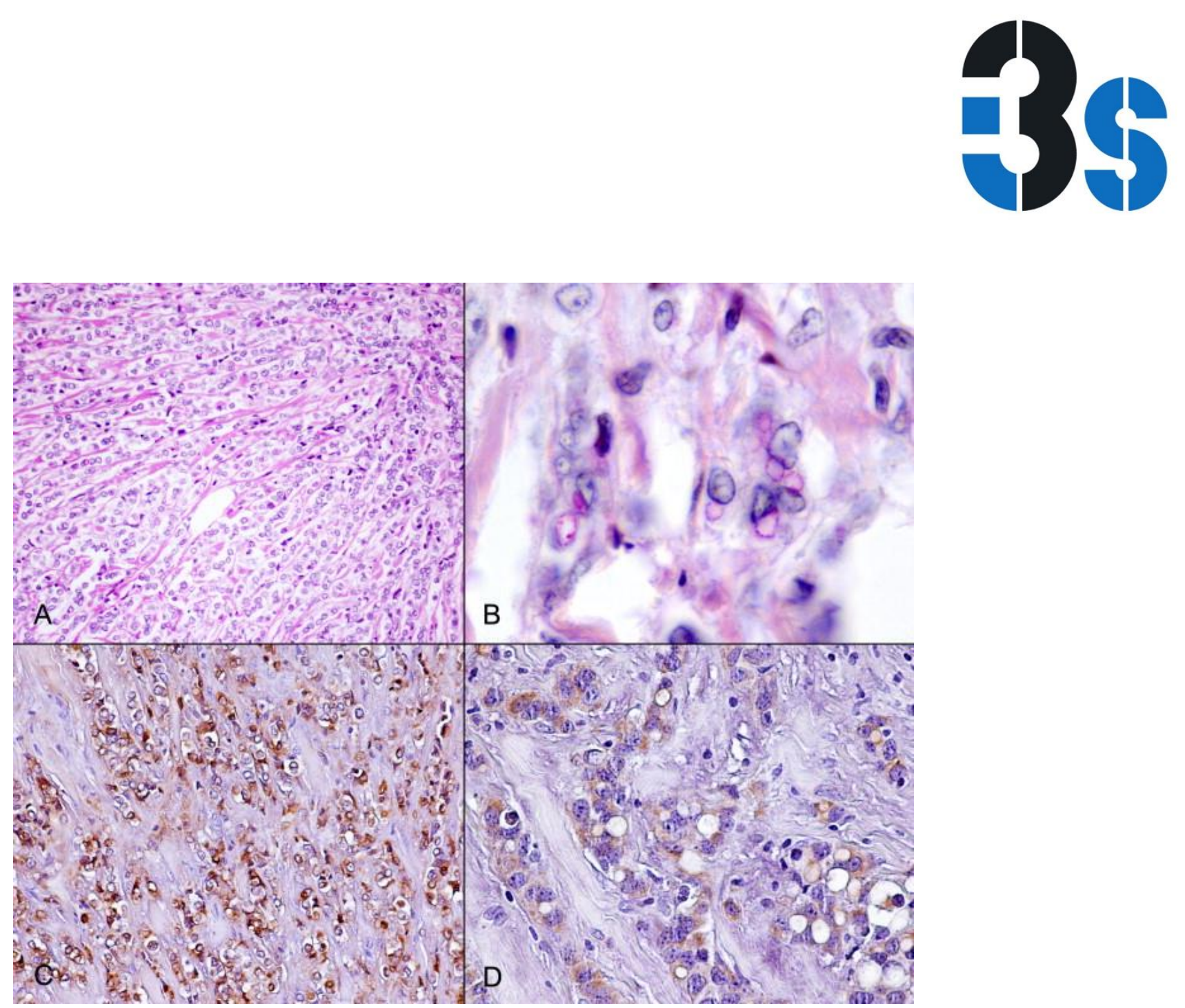

Fig. 3. Lobular carcinoma showing an indian-file like pattern (A: PAS-D, 20x) with abundant signetring cells of the intracytoplasmic lumina type (B: PAS-D, 100x). There is MUC1 (C: 20x) and MUC2 (D: 20x) expression. 

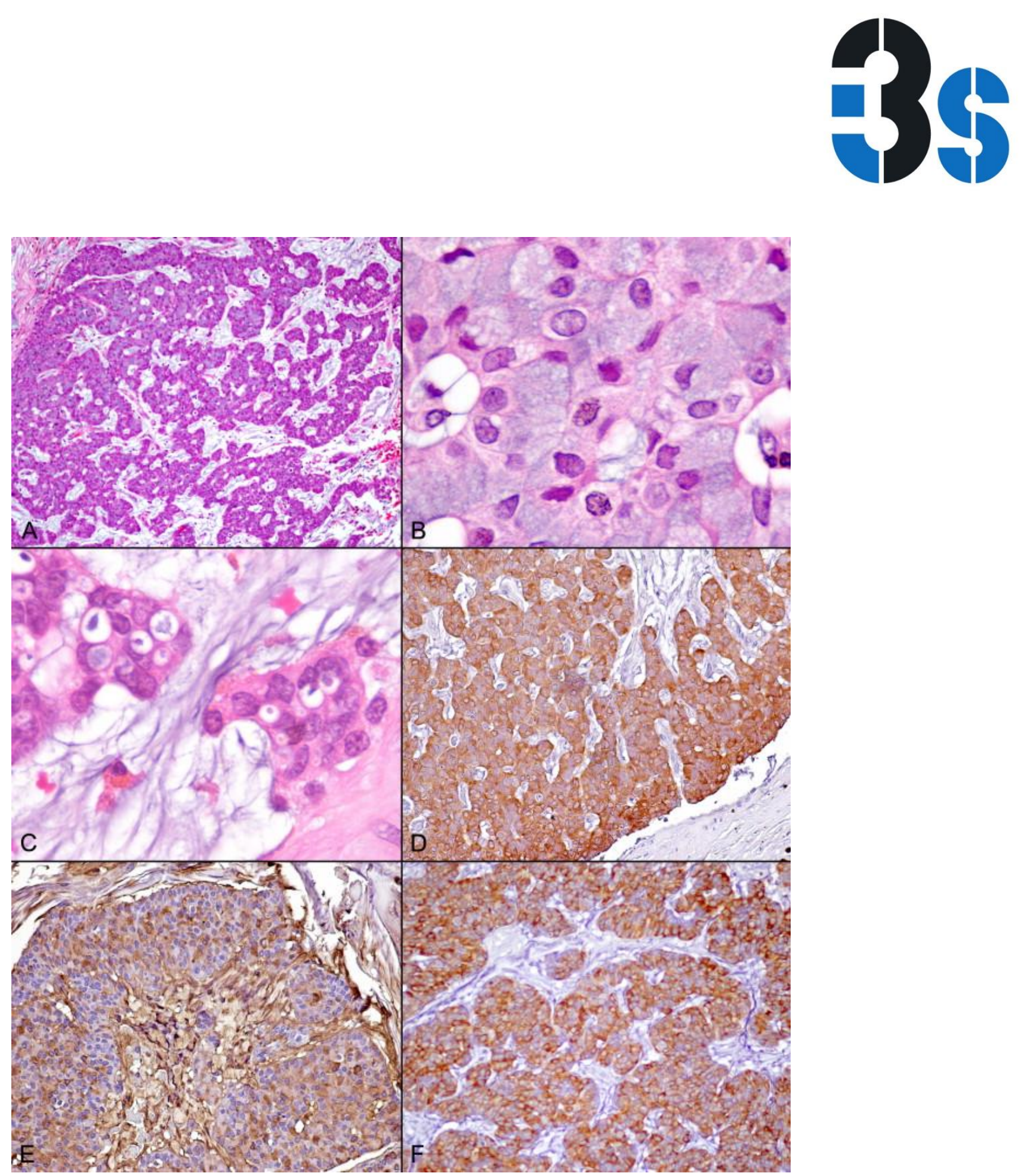

Fig. 4. Mucinous carcinoma with highly cellular areas (A: $H \& E, 10 x)$ showing signet-ring cells both of the goblet-cell type $(B: H \& E, 100 x)$ and intracytoplasmic lumina type (C: $\left.H \& E_{1}, 100 x\right)$. There is $M U C_{1}$ (D: 20x), MUC2 (E: 20x) and MUC6 (F: 20x) expression. 


\section{TABLES}

Table 1

\begin{tabular}{|c|c|c|c|c|c|c|c|c|c|c|c|c|c|c|}
\hline Case & Age & Tumor site & Surgery & $\begin{array}{l}\text { Tumor size } \\
(\mathrm{mm})\end{array}$ & Histologic type & Grade & LVI & $\begin{array}{l}\text { Lymph node } \\
\text { status }\end{array}$ & SRC\% & $\begin{array}{l}\text { Follow-up } \\
\text { (months) }\end{array}$ & Status & ChT & RT & HT \\
\hline 1 & 61 & L-UOQ & TM & 45 & Ductal & 3 & Yes & $\mathrm{n} / \mathrm{a}$ & 24 & 9 & DOD & Yes & Yes & $n / a$ \\
\hline 2 & 82 & R-OQT & Lump & 14 & Ductal & 1 & No & $0 / 4(s n)$ & 23 & 106 & AFD & No & Yes & Yes \\
\hline 3 & 49 & L-UOQ & Lump+nd & 9 & Ductal & 1 & No & $1 / 7$ & 15 & 82 & AFD & No & Yes & Yes \\
\hline 4 & 81 & $\mathrm{~L}-\mathrm{C}$ & TM & 34 & Ductal & 3 & Yes & $\mathrm{n} / \mathrm{a}$ & 51 & 59 & AFD & No & No & Yes \\
\hline 5 & 35 & $\mathrm{R}$ & $\mathrm{TM}+\mathrm{nd}$ & 40 & Ductal & 1 & Yes & $18 / 18$ & 61 & 102 & DOD & Yes & Yes & $\mathrm{n} / \mathrm{a}$ \\
\hline 6 & 77 & L-OQT & $\mathrm{TM}+\mathrm{nd}$ & 23 & Ductal & 2 & Yes & $2 / 7$ & 70 & 87 & AFD & No & Yes & Yes \\
\hline 7 & 34 & $\mathrm{R}-\mathrm{C}$ & $\mathrm{TM}+\mathrm{nd}$ & 23 & Ductal & 2 & No & $1 / 5$ & 31 & 68 & AFD & Yes & No & Yes \\
\hline 8 & 62 & R-UOQ & Lump & $\mathrm{n} / \mathrm{a}$ & Lobular & 1 & No & $0 / 3(\mathrm{sn})$ & 50 & 112 & AFD & No & No & Yes \\
\hline 9 & 83 & R-UQT & Lump+nd & 23 & Lobular & 3 & No & $0 / 11$ & 33 & 87 & DOC & No & Yes & Yes \\
\hline 10 & 54 & L-C & $\mathrm{TM}$ + nd & 85 & Lobular & 2 & Yes & $12 / 12$ & 58 & 2 & DOD & No & Yes & $\mathrm{n} / \mathrm{a}$ \\
\hline 11 & 51 & R-LOQ & $\mathrm{TM}+\mathrm{nd}$ & 33 & Metaplastic & 3 & No & $0 / 14$ & a & 151 & AFD & Yes & No & $\mathrm{n} / \mathrm{a}$ \\
\hline 12 & 85 & $\mathrm{R}$ & TM & 50 & Mucinous & 1 & No & $\mathrm{n} / \mathrm{a}$ & 15 & 13 & DOC & No & No & Yes \\
\hline 13 & 64 & R-UIQ & Lump & 14 & Mucinous & 2 & No & $0 / 2(\mathrm{sn})$ & 16 & 84 & AFD & No & Yes & Yes \\
\hline 14 & 82 & c & $\mathrm{TM}+\mathrm{nd}$ & 40 & Mucinous & 1 & No & $0 / 8$ & 17 & 120 & AFD & $\mathrm{n} / \mathrm{a}$ & $\mathrm{n} / \mathrm{a}$ & $\mathrm{n} / \mathrm{a}$ \\
\hline 15 & 81 & L-UOQ & $\mathrm{TM}+\mathrm{nd}$ & 32 & Mucinous & 1 & No & $0 / 8$ & 8 & 136 & AFD & $\mathrm{n} / \mathrm{a}$ & $\mathrm{n} / \mathrm{a}$ & $\mathrm{n} / \mathrm{a}$ \\
\hline
\end{tabular}

$\mathrm{n} / \mathrm{a}$ - not available/not aplicable. AFD - alive and free of disease; C - central area; Chm - chemotherapy; DOD - dead of disease; DOC - dead of other cause; HT - hormone therapy; L - left; LOQ - lower outer quadrant; LVI - lymphovascular invasion; Lump - lumpectomy; nd - lymph node dissection; OQT - outer quadrant transition; R - right; RT - Ta Lioh

Signet ring cell percentage was not calculated because they were present only in a small focal area.

Immunohistochemistry profile of carcinomas with signet ring cell (SRC) differentiation.

\begin{tabular}{|c|c|c|c|c|c|c|c|c|c|c|}
\hline Case & Histologic type & MUC1 & MUC2 & MUC5AC & MUC6 & ER & E-Cad & Synapt & CD56 & GCDFP15 \\
\hline 1 & Ductal & + & - & - & - & + & + & - & - & + \\
\hline 2 & Ductal & + & - & - & - & + & + & - & - & - \\
\hline 3 & Ductal & + & - & - & - & + & + & - & - & $-a^{a}$ \\
\hline 4 & Ductal & + & + & - & + & + & + & + & - & + \\
\hline 5 & Ductal & + & $-^{a}$ & - & - & + & + & + & - & - \\
\hline 6 & Ductal & + & + & - & + & + & + & $a^{a}$ & - & - \\
\hline 7 & Ductal & + & + & - & + & + & + & - & - & + \\
\hline 8 & Lobular & + & $a^{a}$ & - & - & + & - & - & - & - \\
\hline 9 & Lobular & + & + & - & - & + & - & - & - & + \\
\hline 10 & Lobular & + & + & - & - & $\mathrm{n} / \mathrm{a}$ & - & - & - & + \\
\hline 11 & Metaplastic & + & + & - & - & - & + & - & - & ${ }_{-}^{-a}$ \\
\hline 12 & Mucinous & + & + & - & + & + & + & - & - & + \\
\hline 13 & Mucinous & + & + & - & - & + & + & - & - & + \\
\hline 14 & Mucinous & + & + & + & + & + & - & - & - & + \\
\hline 15 & Mucinous & + & + & - & + & $\mathrm{n} / \mathrm{a}$ & - & + & - & + \\
\hline
\end{tabular}

ER - estrogen receptors; E-Cad - E cadherin; Synapt - synaptophysin. 